\title{
A Revista do IHGB e o saber linguístico: diferentes domínios do saber
}

\author{
Dantielli Assumpção Garcia (UNESP-Ibilce) ${ }^{1}$
}

\begin{abstract}
Resumo: Neste trabalho, analisaremos como o saber linguístico constituiu o discurso da Revista do Instituto Histórico e Geográfico Brasileiro nº400 (1998). Analisaremos como essa revista (RIHGB n ${ }^{\circ} 400$ ) funciona como um índice, isto é, analisaremos como um índice sistematiza, ordena, data e seleciona saberes sobre as línguas do Brasil desde a primeira publicação da Revista (1839) até 1998. Nossa perspectiva teórica é a da Análise de Discurso em articulação com a História das Ideias Linguísticas.
\end{abstract}

Palavras-chave: saber linguístico; Revista do Instituto Histórico e Geográfico Brasileiro; domínio do saber.

\section{Introdução}

Neste artigo, pretendemos analisar como a Revista do Instituto Histórico e Geográfico Brasileiro (doravante RIHGB) no 400, de 1998, constitui-se como um índice em que podemos perceber uma divisão em temas dos textos publicados nas RIHGB anteriores a essa publicação. Nossa proposta justifica-se pelo modo como se categoriza em temas, uma vez que podemos perceber como alguns sentidos vão surgindo, enquanto outros vão sendo apagados, esquecidos, silenciados. Nosso objetivo é analisar o modo como, ao se dividir em temas, atribui-se sentidos às coisas, aos sujeitos, aos espaços, aos acontecimentos brasileiros.

Neste trabalho, discorreremos inicialmente sobre o Instituto Histórico e Geográfico Brasileiro e sua revista e, em seguida, analisaremos as tematizações da RIHGB no 400.

\section{A fundação de um instituto e de sua revista no Brasil do século XIX}

Em 1838, funda-se, na cidade do Rio de Janeiro, a partir de um projeto apresentado à Sociedade Auxiliadora da Indústria Nacional (SAIN) por Januário da Cunha Barbosa e por Raymundo José da Cunha Mattos, o Instituto Histórico e Geográfico Brasileiro (IHGB). Essa instituição se

\footnotetext{
${ }^{1}$ Doutoranda do Programa de Pós-Graduação em Estudos Linguísticos da Universidade Estadual Paulista, campus de São José do Rio Preto. Membro do grupo de pesquisa Paladis. E-mail: dantielligarcia@gmail.com
} 
constitui com o objetivo de "coligir, metodizar, publicar ou arquivar documentos" (Extracto dos Estatutos, RIHGB no 1, 1839, p. 18) relativos à história e à geografia do Brasil. Esses materiais servirão para que seja composta, pelos escritores da sociedade brasileira e internacional, uma história do Brasil. Um lugar em que se pode observar a organização desses textos sobre a história e a geografia do Brasil é a Revista do Instituto Histórico e Geográfico Brasileiro. A RIHGB teve sua primeira publicação em 1839 e mantém sua produção até os dias de hoje. Nela, podemos notar a descrição das atividades da Instituição, os materiais sobre a história e a geografia do Brasil coletados e arquivados na revista. Em meio a esses materiais, encontramos os que dizem respeito ao saber linguístico.

Argumenta Schwarcz que, com a fundação do IHGB, busca-se centralizar o poder e todas as discussões em torno de uma história sobre uma nação em formação:

Com relação ao IHGB, toda a produção intelectual esteve profundamente associada ao Estado Imperial, entendido como "a causa última da unidade política do paiz contra o espírito maligno da anarquia" (RIHGB, 1840, p. 505). Nascido em meio a uma conjuntura em que se luta pela preservação da soberania do país o IHGB identificou-se com a política centralizadora daquele período, mantendo desde a origem a finalidade explícita de construir uma "memória nacional" em que a produção intelectual e relações de poder estivessem tão irmanadas que não haveria lugar para discórdia. "Guardiões do Imperador”, os sócios do IHGB souberam garantir seu espaço no interior da nova organização política justificando a manutenção da unidade interna, causa última de um Estado "que nasceu Império" e debatia-se ante a possibilidade da dissensão (SCHWARCZ, 1993, p. 135).

Por esses dizeres, podemos notar que o papel do IHGB, em uma aliança com o poder Imperial, é também o de uma instituição que almeja manter a ordem da/na sociedade "contra o espírito maligno da anarquia". Nessa instituição, a possibilidade de "discórdia" é descartada, já que todos os "Guardiões do Imperador" estão unidos com o objetivo de construir um espaço para a divulgação de uma memória do Brasil. Schwarcz (1993; 1989) mostra como o Imperador D. Pedro II mantinha fortes relações com o IHGB - era a aliança entre o Estado e uma sociedade da corte. A autora (1993, p. 102) salienta que, desde o início das atividades do IHGB, o Estado representava, com seus donativos, $75 \%$ do orçamento da instituição. A partir dos anos 40, do século XIX, D. Pedro II passa não só a auxiliar como também a frequentar as reuniões do IHGB. Nas palavras do monarca em sua última participação no Instituto: "Agradeço ao Instituto e nada mais digo porque o Instituto sabe que eu sou todo dele" (D. Pedro II). Ao qualificar os sócios como "guardiões do Imperador", Schwarcz (Ibid.) explicita uma relação de 
mão-dupla em que o IHGB sabia que D. Pedro II era "todo dele" e D. Pedro II também sabia que o IHGB era "todo dele". Afinal, os membros eram os seus guardiões, os seus eleitos para coligir um saber sobre o Brasil. Guimarães (1995) mostra que, no final do ano de 1849, o IHGB ganhou novas instalações, situadas no terceiro andar do Paço, ao lado da Capela Imperial. A partir desse momento, a participação de D. Pedro II nas reuniões do IHGB é assídua: "De dezembro de 1849 até a sua partida para o exílio, [D. Pedro II] participou de 508 reuniões ordinárias, sem contar as sessões públicas de aniversário e outras comemorações" (Ibid., p. 487). Sánchez (2003), analisando os títulos da RIHGB, mostra que os mesmos expõem cada vez mais proximidade com o Imperador, assim como uma autonomia junto à Sociedade Auxiliadora da Indústria Nacional (SAIN). Nas palavras da autora:

O título da Revista do IHGB e suas alterações ao longo dos anos podem denunciar outras particularidades do Instituto Histórico. Se em 1839 o título faz menção à Sociedade Auxiliadora da Indústria Nacional [...] logo no ano seguinte a primazia é deslocada para outra esfera. Quando o imperador aceitou o título de protetor do Instituto, foi acrescentado ao final do título. Esta referência começa em 1840, ano da antecipação da maioridade de D. Pedro II, permanece durante todo o longo Segundo Reinado e prossegue além dele: em 1890 o título ainda traz o nome de D. Pedro II (então no exílio) demonstrando em primeira página o comprimento da instituição com o poder imperial (Ibid., p. 58).

Podemos notar como as relações no interior do IHGB vão sofrendo deslocamentos com o passar dos anos. Inicialmente, temos uma relação com uma indústria nacional em formação; depois, essa relação movimenta-se mais para um contexto político - relação com o Imperador. É interessante que essas relações mudam até mesmo em termos de movimento no espaço. No início, o IHGB era localizado na própria SAIN. Em seguida, passa ao Paço Imperial, ficando ao lado da Capela Imperial, fato esse que corrobora para a assiduidade de D. Pedro II nas reuniões da instituição. O IHGB divide o espaço com o poder político, que se centraliza nas mãos de D. Pedro II, e com o poder religioso.

Em relação aos membros do IHGB, podemos perceber, de acordo com Schwarcz (1993, p. 105), que os critérios para a seleção dos membros são "bastante elásticos". De um lado, o intelectual (com trabalhos relacionados à história, à geografia e à etnografia), de outro, o econômico (presente de valor, doações). A instituição, em sua constituição, cumpria diferentes papéis: "para alguns significava um local de projeção intelectual, para outros um espaço de promoção pessoal" (Ibid., p. 105).

Um modo, como já ressaltamos, de produzir/divulgar uma historiografia elaborada pela(os) elite/membros do IHGB foi a Revista do 
IHGB. A Revista tinha um público certo: os sócios do Instituto e as sociedades nacionais e internacionais com as quais o IHGB mantinha contato. A RIHGB, conforme Guimarães (1988), constitui um "foro privilegiado" para notar o projeto historiográfico brasileiro:

Além de registrar as atividades da instituição através de seus relatórios, divulgar cerimônias e atos comemorativos diversos, as páginas da Revista se abrem à publicação de fontes primárias como forma de preservar a informação nelas contidas - aliás, parte substancial de seu conteúdo nos primeiros tempos - de artigos, biografias e resenhas de obras (Ibid., p. 21).

Vejamos, a seguir, como a RIHGB sistematiza esse "projeto historiográfico".

\section{A tematização na RIHGB nº400: os dicionários, as línguas e os índios}

A Revista do IHGB no 400, publicada em 1998, em comemoração aos 160 anos do IHGB, busca dar conta de uma periodicidade de 159 anos da Revista do IHGB. Tal número apresenta um índice dividido em assunto, título e autor. Temos também um texto (Apresentação) do Presidente do IHGB (Arno Wehling) e um texto (Introdução) assinado pela direção da Revista.

Consideramos a Revista do IHGB $\mathrm{n}^{\circ} 400$ um texto documentador que sistematiza a documentação de obras (textos) sobre diversos temas produzidos ou coletados pelo IHGB. De acordo com Nunes (2008), convém distinguir os textos a serem documentados (obras) dos textos documentadores (descrições, comentários, resumos, indexações, bibliografias, periodizações etc.):

Uma obra passa a ser um "documento" na medida em que ela é historicizada, ou seja, na medida em que ela se torna objeto de um saber documental. O texto documental nomeia, data, seleciona objetos e traça percursos. Sua tipologia é variada e caracteriza-se pelo caráter metalingüístico. Por vezes ele se apresenta inserido em um texto teórico, outras vezes apresenta-se como texto de arquivo, com o objetivo reconhecido de documentação (Ibid., p. 83).

A Revista $n^{\circ} 400$ se apresenta com o objetivo de documentação: "fazia falta, entretanto, um índice que cobrisse o conjunto da produção da Revista, atualizado até nossa época e dentro dos moldes técnicos". Assim, com o objetivo de refletir sobre a prática de documentação efetuada pela Revista do $I H G B$, analisaremos quais textos documentais, especificamente relacionados ao saber linguístico, foram reunidos e divulgados nesse texto documentador que se constitui a Revista do IHGB n ${ }^{\circ} 400$.

Nosso objetivo nesta parte é analisar como a RIHGB $n^{\circ} 400$ se divide em temas. Como já ressaltamos, a divisão temática indica alguns sentidos, 
seleciona fatos, apaga acontecimentos. Para essa análise específica, baseamonos na parte do índice Assunto. Analisamos especificamente três temas dessa divisão: Dicionário, Lingua e Índios. Esses temas foram selecionados, porque em todo o nosso trabalho são eles que perpassam a produção sobre um saber linguístico da RIHGB no século XIX. Assim, pretendemos notar como a produção da RIHGB em relação a esses assuntos são tematizados: que textos são contemplados em tais tematizações? Que sentidos circulam? Que sentidos são apagados?

No tema Dicionário e Lingua, temos contemplados os seguintes textos:

\section{Dicionário}

- Dicionário abreviado tupinambá-português: apêndice a Poranduba maranhense, 1891.

- Dicionário da língua geral do Brasil, 1891.

- Dicionário histórico e geográfico das campanhas do Estado Oriental do Uruguai e Paraguai, 1887.

\section{Língua}

- Vocabulário da língua bugre, 1852.

- Explicação conveniente acerca do trabalho de Pablo Restivo sobre a língua guarani, 1895.

- A língua geral do Amazonas e o guarani, 1888.

- Um manuscrito guarani, 1880.

- Palavras guaranis, 1897.

- Partículas de la lengua guarani, 1895.

- Questões propostas sobre alguns vocábulos da língua geral brasiliana, 1882.

- Coleção de vocábulos e frases usados na província de São Pedro do Rio Grande do Sul, 1852.

- Coleção de etimologias brasílicas, 1846.

- Memória sobre a necessidade do estudo e do ensino das línguas indígenas do Brasil, 1841.

- A grammar and vocabulary of the tupi language, 1880.

- Vocabulário da língua geral usada hoje no alto do Amazonas, 1854.

Nessa divisão, podemos notar que as línguas documentadas são: tupinambá, lingua geral do Brasil, lingua geral do Amazonas, lingua geral brasiliana, lingua brasílica, língua tupi, língua geral usada no alto do Amazonas, língua guarani e língua bugre. Ademais, temos uma obra em língua portuguesa que é regionalista (Coleção de vocábulos e frases usados na província de São Pedro do Rio Grande do Sul) e 
uma obra de especialidades (Dicionário Histórico e Geográfico das Campanbas do Estado Oriental do Uruguai e Paraguai). Há somente uma língua (bugre) que não pertence ao tronco Tupi-Guarani ${ }^{2}$, ou seja, as demais línguas fazem parte desse tronco. Essa divisão constitui um imaginário de que as línguas que têm estatuto de língua são as do tronco Tupi-Guarani, além de apagar o multilinguismo existente no Brasil. No texto Memória sobre a necessidade do estudo e do ensino das linguas indígenas do Brasil, podemos notar que não há a indicação de quais línguas indígenas devem ser ensinadas e estudadas. No entanto, essa divisão proposta pela RIHGB $n^{\circ} 400$ permite-nos pensar que somente as línguas do tronco Tupi-Guarani são objetos de um estudo. Cria-se um imaginário de que as "línguas indígenas do Brasil" são somente essas nomeadas nessa parte do índice. De acordo com Barros (1990, s/p.), "no mundo acadêmico do século XIX, o Instituto Histórico e Geográfico Brasileiro foi a principal instituição responsável pela produção e difusão dessa visão normativa do tupi".

O modo como o índice se constitui, por temas (aqui, especificamente, língua e dicionário), encobre a diversidade linguística do Brasil. $\mathrm{O}$ índice leva a pensar que, no espaço de "estudo e ensino" das línguas indígenas do Brasil, só teríamos as línguas gerais (tupi-guarani) e que somente essas línguas foram gramatizadas e objeto de interesse do IHGB. Na RIHGB $n^{\circ} 400$, a língua tupiguarani é que dá unidade ao espaço multilíngue que é o Brasil. É essa imagem de homogeneidade que apaga a diversidade, que se historiciza nessa tematização do índice e que se sustentará no tema Índios.

A tematização Índios se constitui da seguinte forma: há a indicação do grupo indígena mais a indicação do tema do texto referente aos indígenas. Essas tematizações vão indicando os sentidos do índice. Vejamos:

\section{Índios Aimoré - Condições Sociais}

- Qual era a condição do sexo feminino entre os indígenas do Brasil?, 1842.

\section{Índios Apiacá - Mato Grosso}

- Memória sobre os usos, costumes e linguagem dos Apiacás e descobrimento de novas minas na província de Mato Grosso, 1844.

Índios Bororo - Glossários, Vocabulários, etc.

- Vocabulário da língua dos Bororos-Coroados do Estado de MatoGrosso, 1918.

Os temas que são contemplados nessa parte do índice são: condições sociais; glossários, vocabulários, etc; usos e costumes; direitos civis; lendas; relações com o governo; religião e mitologia; línguas - estudo e ensino; dicionários, línguas. A tematização

${ }^{2}$ Pertencente ao Tronco Macro-Jê. 
dicionários e línguas aparece duas vezes. Uma sem a indicação do grupo indígena e outra com a indicação do grupo. Com a indicação só aparece essa estrutura temática uma única vez, fazendo referência aos índios Tupinambá:

\section{Índios Tupinambá - Dicionários}

- Dicionário abreviado tupinambá-português: apêndice a Poranduba Maranhense, 1891.

- Dicionário da língua geral do Brasil, 1891.

Índios Tupinambá - Línguas

- Dicionário abreviado tupinambá-português: apêndice a Poranduba Maranhense, 1891.

- Dicionário da língua geral do Brasil, 1891.

Mais uma vez, tem-se a imagem do tronco Tupi (língua geral, tupinambá) como o tronco legitimado para ser tratado como "língua", "dicionário". Os outros trabalhos relativos a outros grupos indígenas não fazem parte dessa tematização, mas sim do "glossário e vocabulários". A língua indígena legitimada pela RIHGB é a língua Tupi-Guarani, as outras línguas aparecem secundariamente e fazem referência a um saber sobre o índio e não em relação à sua língua.

Os "Vocabulários e Glossários” contemplados nesse índice são:

Índios Bororo - Glossários, Vocabulários, etc.

- Vocabulário da língua dos Bororos-Coroados do Estado de Mato Grosso, 1918.

Índios Caiapó - Vocabulários, Glossários, etc.

- Vocabulários indígenas, 1892.

Índios Caingangue - Glossários, Vocabulários, etc.

- Vocabulário do dialeto caingang, 1888.

Índios Carajá - Vocabulários, Glossários, etc.

- Vocábulos indígenas, 1892.

Índios da América do Sul - Brasil - Glossários, Vocabulários, etc.

- $\quad$ Notas sobre a história pátria, 1876, 1877, 1878, 1879.

- Vocábulos indígenas e outros introduzidos no uso vulgar, 1882.

Índios da América do Sul - Rio de Janeiro (RJ) - Glossários, Vocabulários, etc.

- Os topônimos indígenas do Rio de Janeiro quinhentista, 1967.

Índios Guaná - Glossários, Vocabulários, etc.

- Vocabulário da língua guaná ou xane, 1875.

Índios Munduruku - Glossários, Vocabulários, etc.

- $\quad$ Estudos sobre a tribo Mundurucu, 1877.

Índios Puri - Glossários, Vocabulários, etc. 
- Vocabulário Puri, 1889.

Índios Tukuna - Glossários, Vocabulários, etc.

- Gramática, dicionário, verbos e frases e vocabulário prático da língua dos índios Tucunas, 1944.

Nessa tematização, temos alguns glossários e vocabulários contemplados. Esses não estão presentes na tematização Lingua e Dicionário. Qual seria o critério de tematização? Essas outras línguas não teriam o estatuto de língua? Apagam-se, como já ressaltamos, as línguas pertencentes ao tronco Macro-Jê. A divisão em temas é feita pela nomeação do grupo indígena (índios bororo, caingangue, guaná, mundurucu, puri) e não por sua língua. Esse gesto de documentação apaga as outras línguas e o imaginário de unidade e de representatividade da língua tupi é explicitado. Ademais, podemos perceber uma flutuação nas nomeações: ora o vocabulário é de língua, ora de dialeto, ora é somente pelo nome do grupo indígena, ora aparece sob a nomeação "vocábulos indígenas", não especificando a que grupo pertence. Não há uma estabilidade nessas nomeações.

As línguas do tronco Tupi-Guarani aparecem nas três tematizações: Dicionários, Linguas e Índios. Essa repetição reforça o imaginário de que as línguas indígenas do Brasil pertencem ao tronco Tupi-Guarani.

Além disso, por essa tematização, podemos dizer que há uma separação do sujeito leitor. O índice divide a sociedade, os sujeitos. $\mathrm{Na}$ tematização Lingua e Dicionário, teríamos textos direcionados a linguistas, a estudiosos das ciências da linguagem. Já na tematização Índios, ao sujeito antropólogo. Por isso as outras tematizações trazidas ao tema Índios. Ao sujeito antropólogo interessa as condições sociais, os usos, os costumes, os direitos civis, as lendas, a religião, a mitologia dos indígenas. Para produzir um saber sobre o indígena, é necessário saber sobre a vida desses, além da língua que falam.

Finalizando, na análise desses temas, pudemos perceber a nãocompletude ao categorizar-se, as falhas, os equívocos que um gesto de documentação produz no real e no imaginário da linguagem. Apagam-se alguns sentidos para tornar transparentes outros.

A Revista $n^{\circ} 400$, como um texto documental, estabiliza sentidos e vai construindo um discurso da história em que podemos ver como as línguas do tronco Tupi-Guarani, em uma relação de força, se sobrepõem às línguas de outros troncos indígenas, tais como do tronco Macro-Jê, e criam um imaginário de unidade, de homogeneidade. Embora até se apresente a diversidade das línguas do Brasil, esta é homogeneizada na tematização, gerando, assim, um apagamento do multilinguismo existente no Brasil desde o início da colonização. Esse apagamento foi pelo extermínio dos indígenas, por 
sua catequização, contudo, também foi, como buscamos apontar, pelo controle dos sentidos, pela imposição de uma unidade à diversidade.

\section{Considerações finais}

Buscamos mostrar, neste artigo, como, por meio de um trabalho de arquivo, de documentação, não é permitido aos sujeitos esquecer saberes que são constituídos e divulgados para as línguas do Brasil. Afinal, o arquivo está guardado, preservado no interior da instituição chamada Instituto Histórico e Geográfico Brasileiro. Assim, guardando dizeres e saberes, o IHGB vai constituindo um discurso oficial e nacional para as línguas do Brasil.

\section{Referências}

AUROUX, Sylvain. A revolução tecnológica da gramatização. Campinas, SP: Editora da Unicamp, 1992.

COLLINOT, André; MAZIÈRE, Francine. Un prêt à parler: le dictionnaire. Paris: Presses Universitaires de France, 1997.

GUIMARÃES, Manoel Luiz Salgado. Uma história da história nacional: textos de fundação. Disponível em: <www.coresmarcasefalas.pro.br/adm/anexos/1122008005626.pdf>. Acesso em: 20 jan. 2010.

- Nação e civilização nos trópicos: o instituto histórico e geográfico brasileiro e o projeto de uma história nacional. Estudos Históricos, Rio de Janeiro, n. 1, 1988, p. 5-27.

NUNES, José Horta. Dicionários no Brasil: análise e história do século XVI ao XIX. Campinas, São Paulo, São José do Rio Preto: Pontes, Fapesp, Faperp, 2006.

- O discurso documental na história das idéias lingüísticas e o caso dos dicionários. Alfa. 2008.

ORLANDI, Eni. Análise de discurso: princípios e procedimentos. Campinas, SP: Pontes, 2002.

RODRIGUES, Aryon Dall'Igna. Línguas brasileiras. Para o conhecimento das línguas indígenas. São Paulo: Loyola, 2002.

. Línguas indígenas: 500 anos de descobertas e perdas. D.E.L.T.A, vol. 9, n.1, p. 83-103, 1993.

SÁNCHEZ, Edney Christian Thome. 221f. Revista do IHGB: um periódico na cidade letrada brasileira do século XIX. Dissertação de Mestrado, Universidade Estadual de Campinas, IEL. Campinas, SP: IEL, 2003. 
SCHWARCZ, Lilia Moritz. O espetáculo das raças: cientistas, institutos, instituições e questão racial no Brasil: 1870-1930. São Paulo: Companhia das Letras, 1993.

Guardiões de nossa história oficial. São Paulo: Idesp, 1989. 